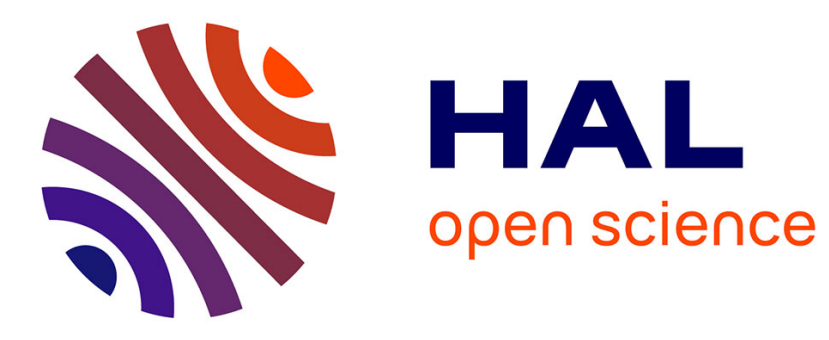

\title{
Thermal aging influence on the damage mechanisms of fully recycled composite-reinforced polypropylene/polyethylene blend
}

Hassen Meftah, Sahbi Tamboura, Joseph Fitoussi, Hachmi Bendaly, Abbas Tcharkhtchi

\section{To cite this version:}

Hassen Meftah, Sahbi Tamboura, Joseph Fitoussi, Hachmi Bendaly, Abbas Tcharkhtchi. Thermal aging influence on the damage mechanisms of fully recycled composite-reinforced polypropylene/polyethylene blend. Polymer Composites, 2019, 40 (8), pp.3342-3350. 10.1002/pc.25194 . hal02428493

\section{HAL Id: hal-02428493 \\ https://hal.science/hal-02428493}

Submitted on 6 Jan 2020

HAL is a multi-disciplinary open access archive for the deposit and dissemination of scientific research documents, whether they are published or not. The documents may come from teaching and research institutions in France or abroad, or from public or private research centers.
L'archive ouverte pluridisciplinaire HAL, est destinée au dépôt et à la diffusion de documents scientifiques de niveau recherche, publiés ou non, émanant des établissements d'enseignement et de recherche français ou étrangers, des laboratoires publics ou privés. 


\title{
Thermal Aging Influence on the Damage Mechanisms of Fully Recycled Composite-Reinforced Polypropylene/Polyethylene Blend
}

\author{
Hassen Meftah $\mathbb{D}^{1,},{ }^{1,2}$ Sahbi Tamboura, ${ }^{1}$ Joseph Fitoussi, ${ }^{2}$ Hachmi BenDaly, ${ }^{1}$ Abbas Tcharkhtchi ${ }^{2}$ \\ ${ }^{1}$ LMS, ENISo, Université de Sousse, BP 264 Cité Erriadh, 4023, Sousse, Tunisie \\ ${ }^{2}$ Laboratoire PIMM, UMR 8006 CNRS, Arts et Métiers Paris-Tech, Paris, 75013, France
}

\begin{abstract}
The main aim of this work is to study the effect of thermal aging on damage mechanisms of a totally recycled composite. The studied material was elaborated by injection molding from a mixture of both recycled matrix (polypropylene-polyethylene blend) and reinforcement (short carbon fibers). Damage mechanisms analysis was carried out using scanning electron microscope (in situ three point bending tests performed on specimens taken at different times of oxidation under different temperatures: 120,130 , and $140^{\circ} \mathrm{C}$. Damage mechanisms were identified for different material states. It was shown that thermal aging affects the fiber-matrix interfacial zone while good adhesion between the reinforcement and the matrix was observed for the virgin sample. Furthermore, a quantitative analysis was performed at the local scale in a representative zone of the tensile area. Representative local damage indicators were defined. Results display clearly that damage evolutions always begin during the induction period. Thermal aging effect was then analyzed through the comparison of damage thresholds and kinetics for different material states after different times of oxidation.
\end{abstract}

\section{INTRODUCTION}

With the increasing demands for lighter and more efficient composites, the need of recycled materials has increased as well due to environmental awareness $[1,2]$. Glass and carbon fibers ( $\mathrm{GF}$ and $C F$ ) represent $>95 \%$ of the composites reinforcement worldwide, but from a mechanical and economic point of view after recycling, $C F$ are the best choice to be recycled [3]. In fact, after recycling, $C F$ preserve more than $90 \%$ of their mechanical properties compared with only $30 \%$ for GF $[4,5]$. During composites use, especially in aeronautic and automotive applications, different components are subjected to high temperatures and stresses well over their elastic limit. Damage and failure mechanisms associated to composites are various and complex. Fiber/matrix interface weakening is the most frequent observed damage initiation mechanism leading to final failure through micro-cracks coalescence [6-8]. Indeed, many authors have focused their studies, on one hand on the characterization of damage for composites trying to well understand damage mechanisms and on the other hand on predicting this damage through micromechanical models [9-11]. In fact, damage is conditioned by local damage criterion at the fiber/matrix interface and a viscoplastic constitutive model type DSGZ [12] in order to determine micro-cracks density of local damage "d".

Moreover, several authors reported that damage starts at the fiber ends and propagates along the interface [13-15] before coalescence through matrix and failure. However, although the environmental conditions influence, mainly oxidation in the case of PP-based composites, on the mechanical and physical properties have been investigated for many years and well understood [16-18], few studies were realized on the thermal aging influence on the local damage mechanisms of CFs-reinforced polymer. Some of previous papers [19-21] dealing with oxidation effect on in situ damage investigation have shown that the generation of micro-cracks creates paths for oxygen to penetrate through the fiber-matrix interface. Thus the interface is oxidized and the material lifetime is consequently reduced.

Studying kinetics of different kinds of damage mechanisms involved in tensile or bending tests allows a better and more accurate modeling of the composite overall mechanical behavior subjected to thermal aging. The intent of this article is to investigate qualitatively and quantitatively the influence of thermal aging on the damage mechanisms of a totally recycled composite (RPP-CF180) intended for crashworthiness improvement in the automotive industry [17] and demonstrate the existence of direct link between the thermal aging and the local damage kinetics. Therefore, scanning electron microscope (SEM) in situ three points bending tests were performed on different specimens taking at different times of oxidation at 120,130 , and $140^{\circ} \mathrm{C}$. The 
obtained results enabled the understanding of the oxidation effect on the fiber/matrix interface and were used to analyze the damage surface and the number of damaged fibers kinetics through aging.

\section{MATERIAL AND EXPERIMENTAL}

\section{RPP-CF180 and Microstructure Description}

The material used for this study is new fully recycled CFsreinforced polypropylene/polyethylene blend (RPP). The fibers were obtained by pyrolysis and then milled to get an average nominal length of $180 \mu \mathrm{m}$ and a diameter of $7 \mu \mathrm{m}$. As for the matrix, it was recycled by a chemical process and designed to better absorb shock waves during collision. For confidential reasons, the exact structure, formula and elaboration process of the matrix will not be communicated. The composite was elaborated by compounding the RPP granulates and $20 \%$ wt fibers using a twin screw extruder Haake Termo PTW 16 -40D. The extruder was operating at a total throughput of $700 \mathrm{~g} / \mathrm{h}$ with a screw speed of $150 \mathrm{rpm}$ and a die temperature of $210^{\circ} \mathrm{C}$. Once the RPP-CF 180 compound was made, it was transferred into an injection molding machine to obtain rectangular plates of 2.5-mm thickness [22]. Microscopic investigation of the composite microstructure was performed using SEM (see Fig. 1).

SEM observations reveal a microstructure carracterized by a shell-core layer formation through the material thickness. Such microstuctrure is frequent for thermoplastic composite elaborated by injection molding process [22-25]. The shell layers are characterized by oriented fibers in the same mold flow direction (MFD) and are the most dominant with $85 \%$ of the plate thickness. As for the core layer, it fills up to $15 \%$ of the plate thickness and the fibers are oriented perpendicularly to the MFD.

\section{Specimen Choice and Preparation}

For the in situ characterization, the specimens were chosen in transversal (perpendicular) direction to the MFD from the plates obtained by injection molding. This choice will be discussed in paragraph 3.1. The samples were 50-mm long with $10-\mathrm{mm}$ width and were taken at different periods of oxidation for each exposure temperature. The polishing procedure used involved $5 \mathrm{~min}$ each of 1,000 , 2,400 , and 4,000 wet grit paper disc sanding. The acceleration voltage used for the SEM was $7 \mathrm{KV}$ and in order to counteract the effect of polymer charging, the specimens were sputter coated with a gold alloy.

The choice of the specimens was made following the elongation at break and the carbonyl build-up evolutions during thermal aging as described in Fig. 2. This mechanic behavior was characterized through tensile tests at quasistatic loading $\left(10^{-2} \mathrm{~s}^{-1}\right)$ on composite specimens taken at different time of aging. These results were obtained in previous work [26] and it has been proven that with the increase of the exposure time, only the elongation at break is affected. Figure 2 shows that from the first moments of exposure (during the induction period) the elongation at break for quasi-static tensile tests drops dramatically by $45 \%$. This important decrease of the elongation at break can be explained by a weakening of the matrix due crosslinking mechanism and chains cut or/and an embrittlement of the composite microstructure more precisely the fiber/ matrix interface weakening. Therefore it is important to choose the first aged specimen during this period in order to emphasize the local mechanisms at the origin of the brutal embrittlement occurring just before the beginning of oxidation $\left(t_{i C O}\right)[13,14]$. The second specimen was taken once the oxidation products start to appear and the third one when the oxidation process begins to stabilize.

\section{In Situ SEM Bending Tests}

In situ tests were realized by positioning the specimens in the SEM chamber (HITACHI 4800 II) and subjecting them to flexural loading using three-point bending device (DEBEN) with a span length of $27 \mathrm{~mm}$. The real time display of force-extension curve is controlled using the DEBEN acquisition software. The contact center crosshead

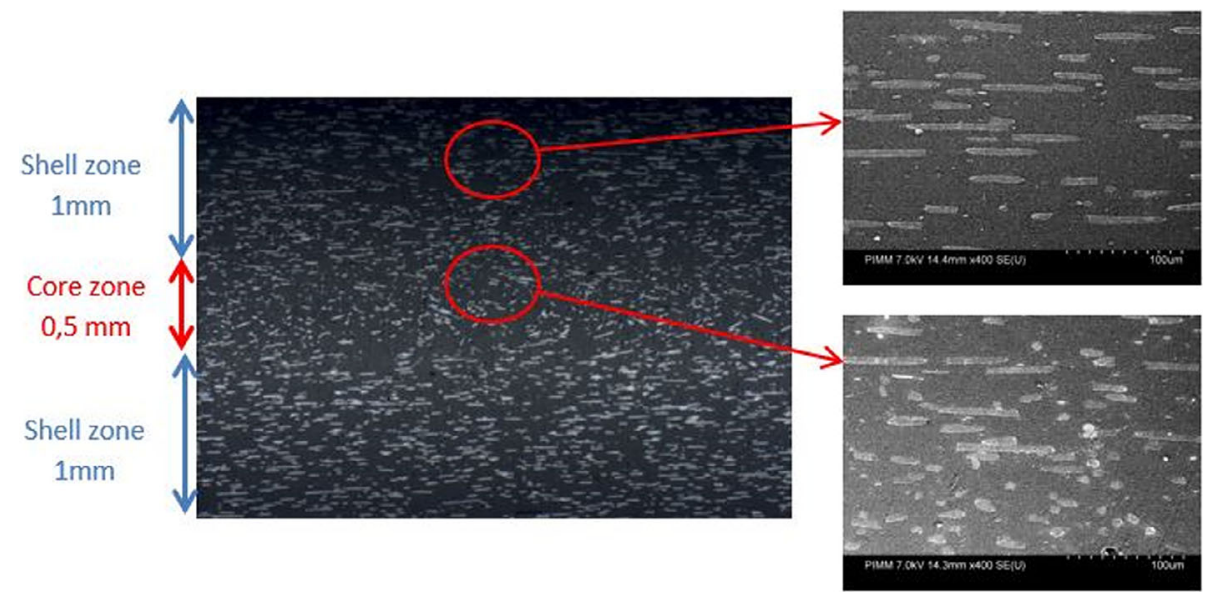

FIG. 1. RPP/CF180 microstructure investigation. [Color figure can be viewed at wileyonlinelibrary.com] 


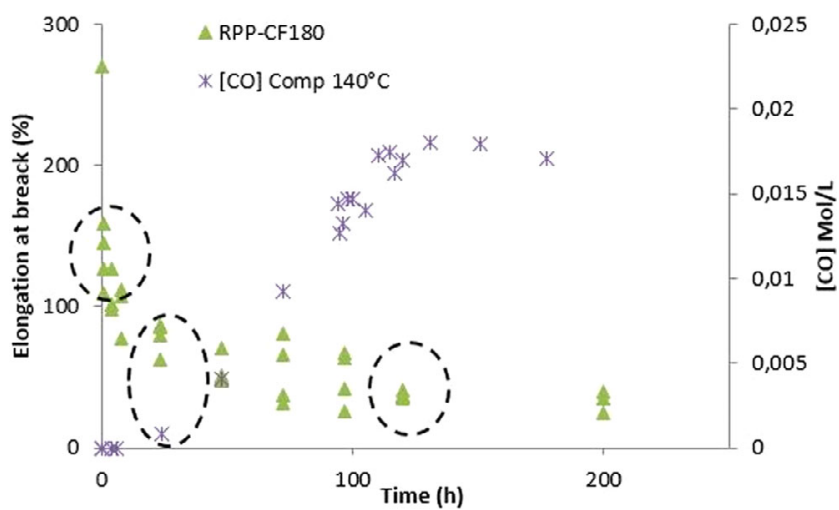

FIG. 2. Elongation at break and carbonyl growth evolutions during thermal aging at $140^{\circ} \mathrm{C}$. [Color figure can be viewed at wileyonlinelibrary.com]

speed was set up to $0.2 \mathrm{~mm} / \mathrm{min}$. In order to be able to acquire images during the test, the displacement of the crosshead was interrupted in fixed positions while applying a constant load. The observation period was limited to 3 min to reduce the relaxation effect of the composite [6] (see also Fig. 5). The observations were focalized on the specimen thickness surface especially at the tensile region.

Since the main objective of this work is also to quantify the effect of thermal aging on the damage mechanisms, the SEM observation were carried out in the shell layer subjected to tension (Fig. 3b) of the specimen at a distance of 200-250 $\mu \mathrm{m}$ from the surface. In order to obtain statistically significant results, an area of $125 \times 80 \mu \mathrm{m}$ was chosen as a representative zone.

\section{EXPERIMENTAL RESULTS AND DISCUSSION}

\section{Effect of Thermal Aging on the Fiber/Matrix Interface}

As mentioned earlier in Section "Specimen choice and preparation", the embrittlement in the composite occurs from the first moments of exposure and the elongation at break drops by $45 \%$ to reach $90 \%$ at the end of oxidation. Thus, in order to identify the mechanisms involved in this embrittlement, SEM analysis of the microstructure were carried out on a virgin sample and other aged samples taken at different times of aging. Figure 4 shows the effect of thermal aging on the fiber/matrix interface of RPP-CF180 at different time of aging at $140^{\circ} \mathrm{C}$. One can easily notice that with the increase of exposure time, small interstices start to appear around the fibers while the virgin sample shows a good adhesion between the reinforcement and the matrix. In fact, after $12 \mathrm{~h}$ of exposure, which corresponds to a few hours before the induction time, interstices (recalling micro-cracks) start to appear covering 20-30\% of the interface perimeter. The micro-cracks spread around the fiber to cover more than $40 \%$ of the fiber perimeter after $40 \mathrm{~h}$ of aging and almost the whole fiber after $100 \mathrm{~h}$ of exposure. In order to be representative, the fiber/matrix interface weakening has been validated for the three aging temperatures at different observation area for several samples.

The appearance of these micro-cracks allows consequently the penetration of the oxygen during thermal aging and so extends the oxidized layer. Therefore, because of the embrittlement of the interface, in situ bending tests were performed on transversal specimens in order to highlight the oxidation effect on the interface.

\section{Micro-Damage Evolution}

Qualitative Analysis. In situ three points bending tests were performed while maintaining the same procedure for all the specimens taken at three different periods of thermal aging for the different exposure temperatures. Figure 5 represents the force/displacement curve of an aged specimen taken after $30 \mathrm{~h}$ at $140^{\circ} \mathrm{C}$, just after the induction time. It shows clearly the interruption of the crosshead displacement needed to take photos of damage initiation and propagation. One can observe that the interruption stages are not enough long to produce significant relaxation of the matrix.

Figure 6 describes the micro-cracks propagation and evolution in the tensile zone of the tested sample thickness for the same specimen. It shows that the initial form of failure is fiber/matrix debonding which is a very common mechanism for short fiber-reinforced composites due local stress concentration at the interface [5]. Besides, the micros-cracks appearance around the fibers with the increase of exposure time weakens the interface and favors the early initiation of cracks which generates an expansion (a)

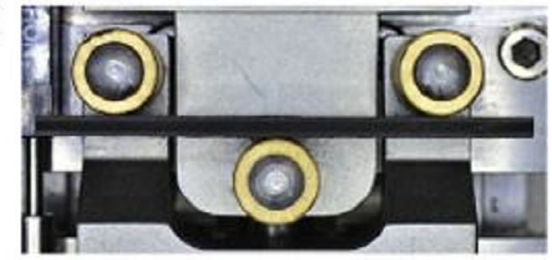

(b)

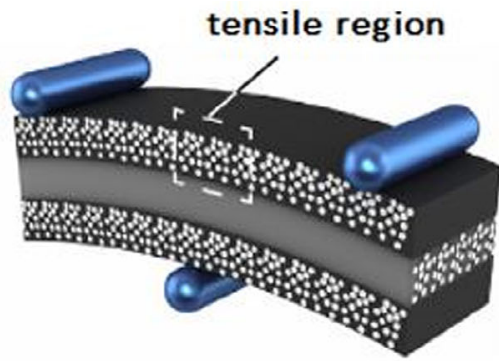

FIG. 3. SEM bending test device: (a) image from experiments (b) illustrated image [11]. [Color figure can be viewed at wileyonlinelibrary.com] 

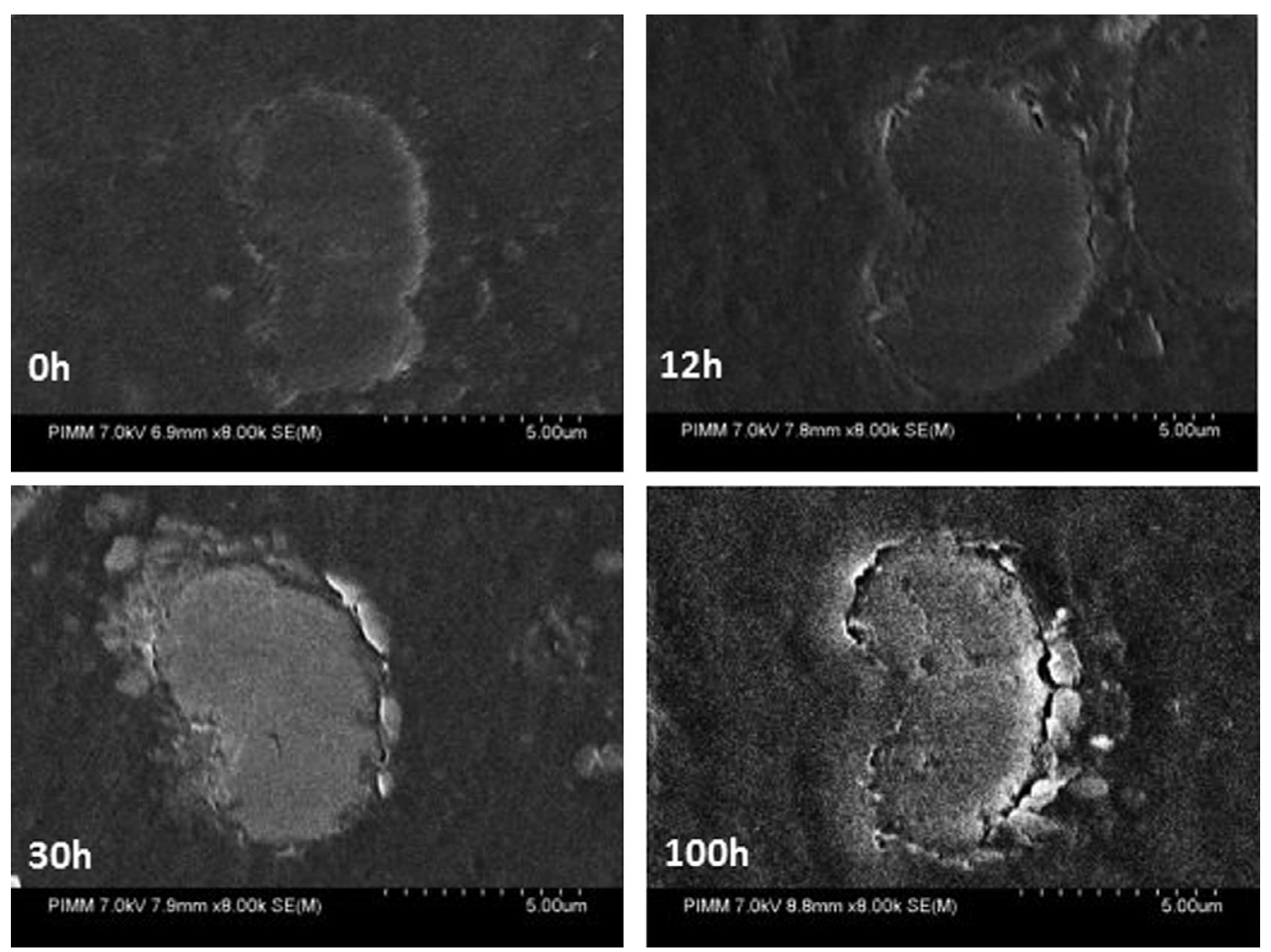

FIG. 4. Thermal oxidation effect on the fiber/matrix interface zone at $140^{\circ} \mathrm{C}$.

of the damaged. Therefore, final failure occurs faster with increasing thermal aging time as described above in Fig. 2.

Qualitatively, one can conclude from in situ bending tests that the same phenomenon occurs for all temperature of aging. Figure $6 \mathrm{~b}$ and $\mathrm{c}$ reveals that once sufficient fiber/ matrix debonding appears, failure spread in the form of micro-crack growth linking the closest debonded fibers through matrix cracking. The marked zones in Fig. $6 \mathrm{~d}$ and e indicate that matrix cracking grows beyond the interfaces bridging the gaps between the fiber-matrix interfaces causing a total propagation of the cracks meanwhile other new micro-cracks start to appear developing a new damaged area [27]. Thus, one can conclude that two mechanisms occur simultaneously: fiber-matrix interface degradation and micro-cracks coalescence and opening.

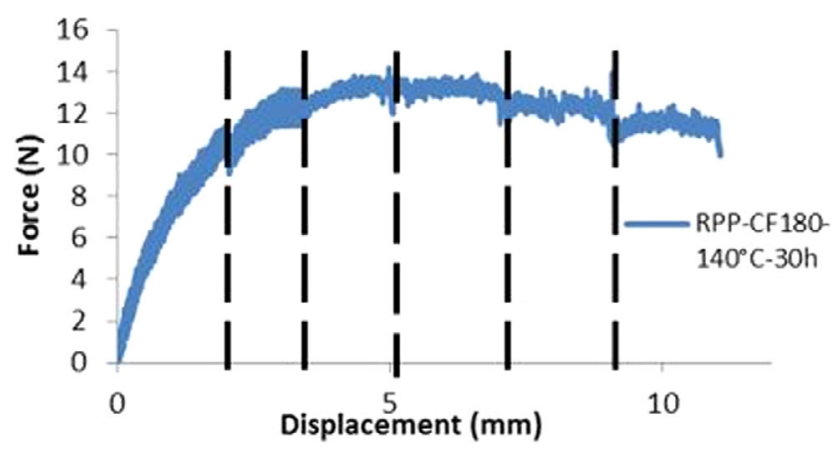

FIG. 5. In situ three points bending curve of RPP-CF180 after $30 \mathrm{~h}$ of aging at $140^{\circ} \mathrm{C}$. [Color figure can be viewed at wileyonlinelibrary.com]
Quantitative Analysis. Thereby, one can define two local damage indicators: the first one is related to the evolution of the density of the fibers submitted to interface damage $(d f)$ given by:

$$
d f=\frac{\text { damged fibers }}{\text { Total of fibers }} \times 100
$$

The second indicator $(d S)$ is related to the opened overall surface of the micro-cracks.

The evolutions of damaged fibers and the total damaged surface in the representative tensile zone of the specimens for each temperature were obtained by image analysis using ImageJ software are represented in Fig. 7. The represented values of $d f$ and $d S$ are average values for the tested samples. It is obvious that the two damage indicators increase with the increase of exposure time. Furthermore, one can note that, on one hand, the interface damage density increases progressively during aging even during induction time. On the other hand, the damaged surface does not evolve significantly during the induction period, but increases rapidly once the induction time is reached. One should notice that damage threshold (approximately at 1.5 and $3 \mathrm{~mm}$ of imposed displacement for $d f$ and $d S$, respectively) seems to be insensitive to aging. Once this latter is reached, the interface damage indicator start to increase. Thus, the interface damage and micro-crack surface growth kinetics for the different temperatures can be determined from the initial curves slopes after reaching damage threshold as represented in Fig. 8. It is important to emphasize that 
(a)

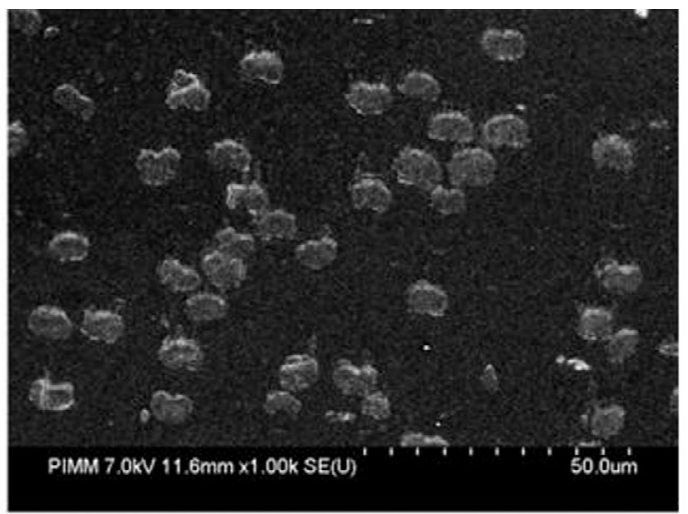

(b)

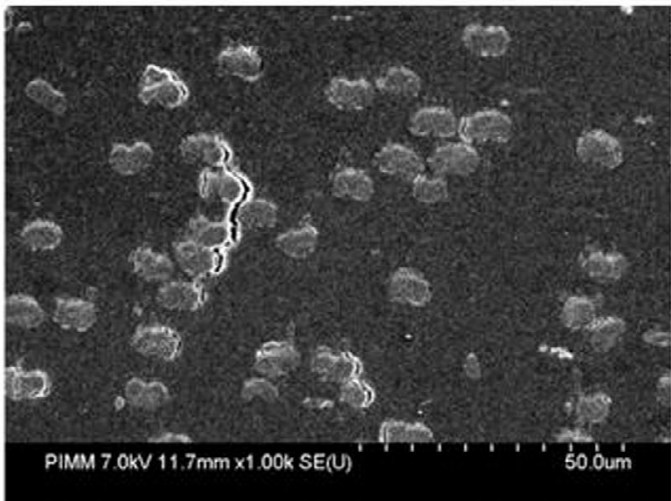

(c)

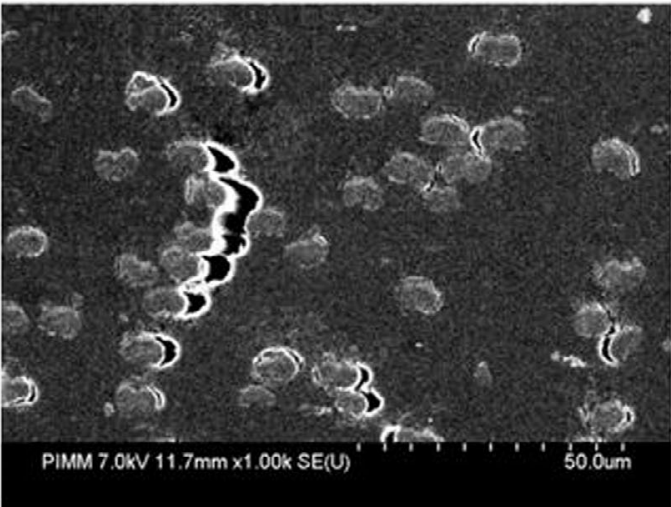

(d)

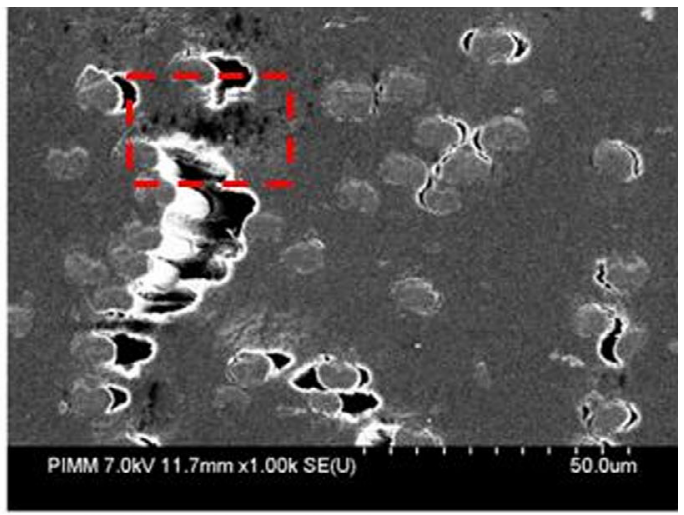

(e)

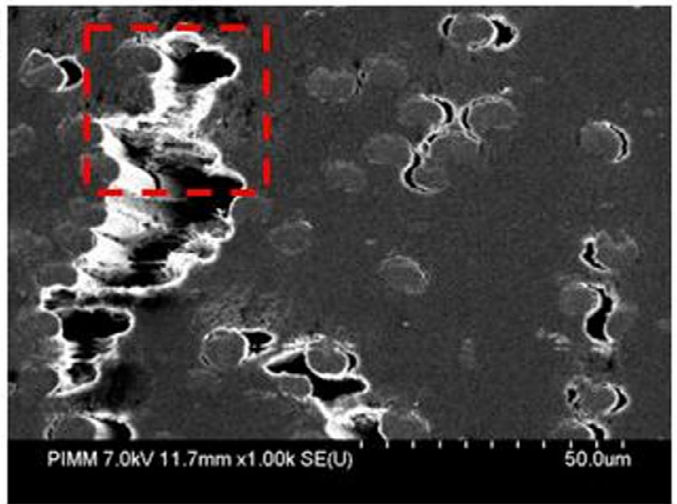

(f)

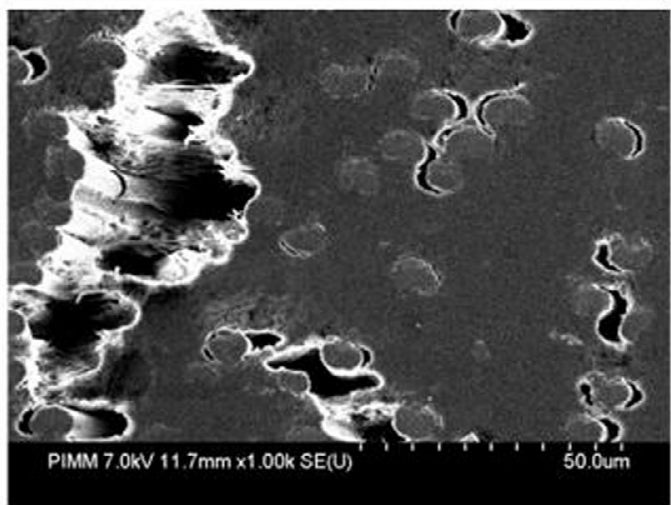

FIG. 6. Cracks evolution of an aged specimen after $30 \mathrm{~h}$ at $140^{\circ} \mathrm{C}$ : (a) $2 \mathrm{~mm}$, (b) $3 \mathrm{~mm}$, (c) $5 \mathrm{~mm}$, (d) $7 \mathrm{~mm}$, (e) $9 \mathrm{~mm}$, and (f) $11 \mathrm{~mm}$ of displacement. [Color figure can be viewed at wileyonlinelibrary.com]

the interface damage increases rapidly till $80 \%$ and then changes its slope. Moreover, it can be noted for instance that a specimen taken after only $30 \mathrm{~h}$ of exposure at $140^{\circ} \mathrm{C}$ reaches $80 \%$ of $d f$ once $5 \mathrm{~mm}$ of imposed displacement is applied while this value is reached after $11 \mathrm{~mm}$ of imposed displacement for a virgin specimen. Thereby, the fiber damage kinetic $(\dot{d} f)$ is coherent only for $d f$ values below $80 \%$.

The $\dot{d} f$ curves are characterized by two linear slopes: a first increase during the induction period caused by the initial micro-cracks appearance around the fibers, as mentioned earlier, and a second greater one observed once the carbonyls start to grow.

Furthermore, during tensile or bending tests, Van der Waals forces are equally distributed on the composite; however the non-sized fiber/matrix interface strength is essentially due to these latter. In the case of our study, the interface becomes weaker during aging through the appearance of micro-cracks around the fibers beside matrix embrittlement which favors the early initiation of damage around the fibers.

As for the damage surface kinetics $(\dot{d} S)$, they show a slight linear increase of about 5\% during the induction period followed by an important one resulting on the fiber/ matrix and matrix weakening.

The surface quantification scatters from a specimen to another even if they have been subjected to the same aging and were taken out of the oven simultaneously. Thus, a statistical analysis should be performed on a representative number of specimens. Therefore, only damage occurring around the fibers $(d f)$ will be considered for further numerical medialization [28].

In previous work [26], a kinetic model based on a standard mechanistic scheme was proposed to predict the carbonyl 

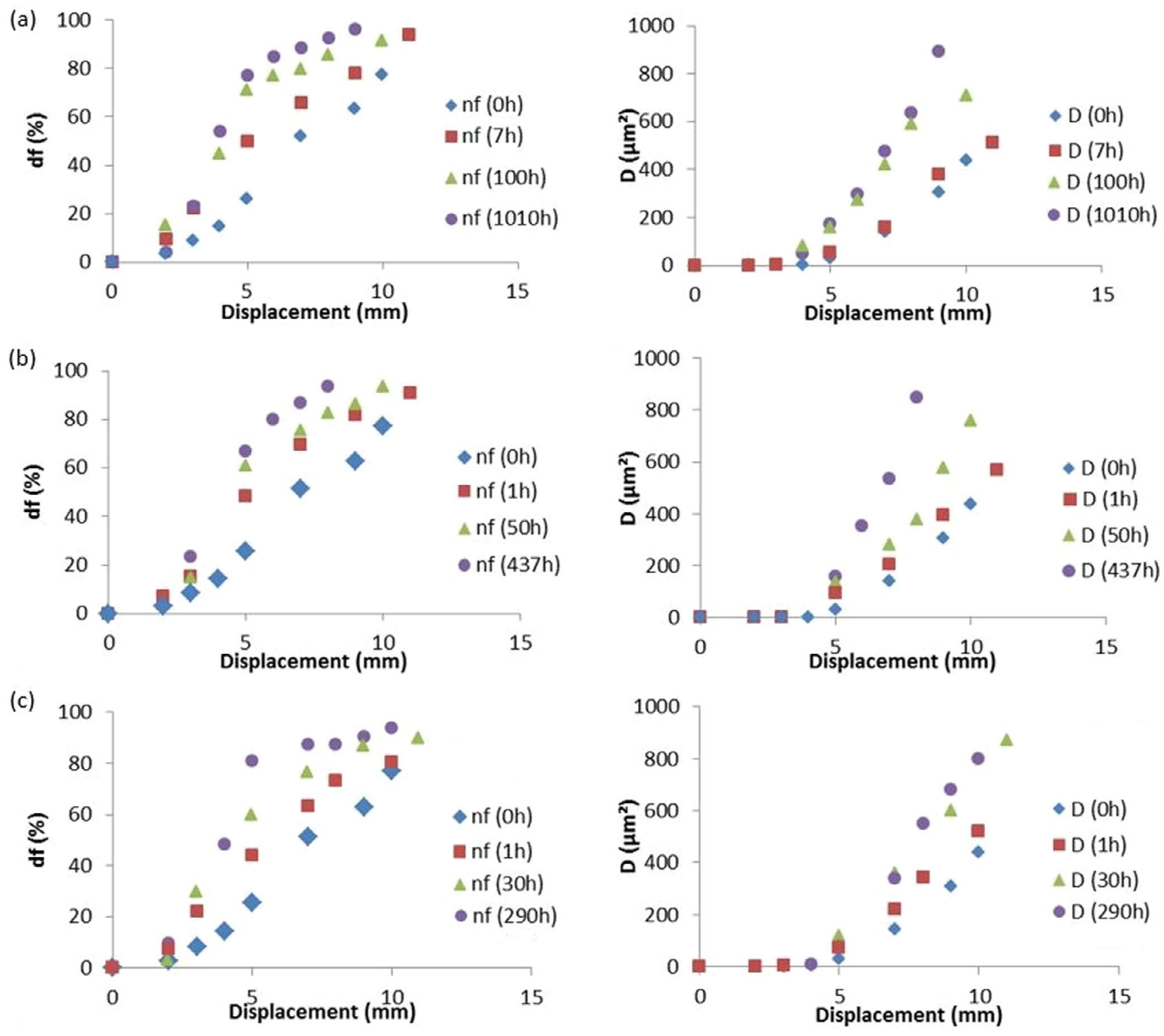

FIG. 7. Damaged fibers and damage evolutions: (a) $120^{\circ} \mathrm{C}$, (b) $130^{\circ} \mathrm{C}$, and (c) $140^{\circ} \mathrm{C}$. [Color figure can be viewed at wileyonlinelibrary.com]

build-up evolution and the antioxidants disseverance in the composite and its matrix at the different temperatures of exposure. This model is also capable of determining low values of the oxidation products, [CO], at the induction period so a link is directly made between the mechanical properties affected by the aging (elongation at break Fig. 2) and the quantity of [CO] present within the material. Thus, the damaged fibers kinetics $\dot{d} f$ for each temperature is linked directly to quantity of the carbonyl within the material and the obtained results are represented in Fig. 9. This result shows clearly that regardless of the exposure temperature, the damage kinetics follow a unique logarithmic law given by:

$$
\dot{d f}=1.1066 \ln ([C O])+25.664
$$

Once the $d f$ evolution as function of [CO] is established, the numerical damaged fibers values $(d f)$ can be determined by reverse method. Since $\dot{d} f$ is the initial linear slope of the damaged fibers curves till $80 \%$, only the corresponding $d f$ values can be determined and are given by:

$$
d f=\dot{d} f\left(d-d_{0}\right)
$$

where $d$ is the imposed displacement and $d_{0}$ is the displacement corresponding to the damage threshold.

Furthermore, the imposed displacement $d$ for a three points bending test can be written as function of the strain $\varepsilon$ :

$$
\varepsilon=\frac{6 h}{l 2} d
$$

where $h$ is the specimen thickness and $l$ is the length between the two supporting pins.

It should be recalled that the purpose of this work is to prove qualitatively and quantitatively the existence of a 

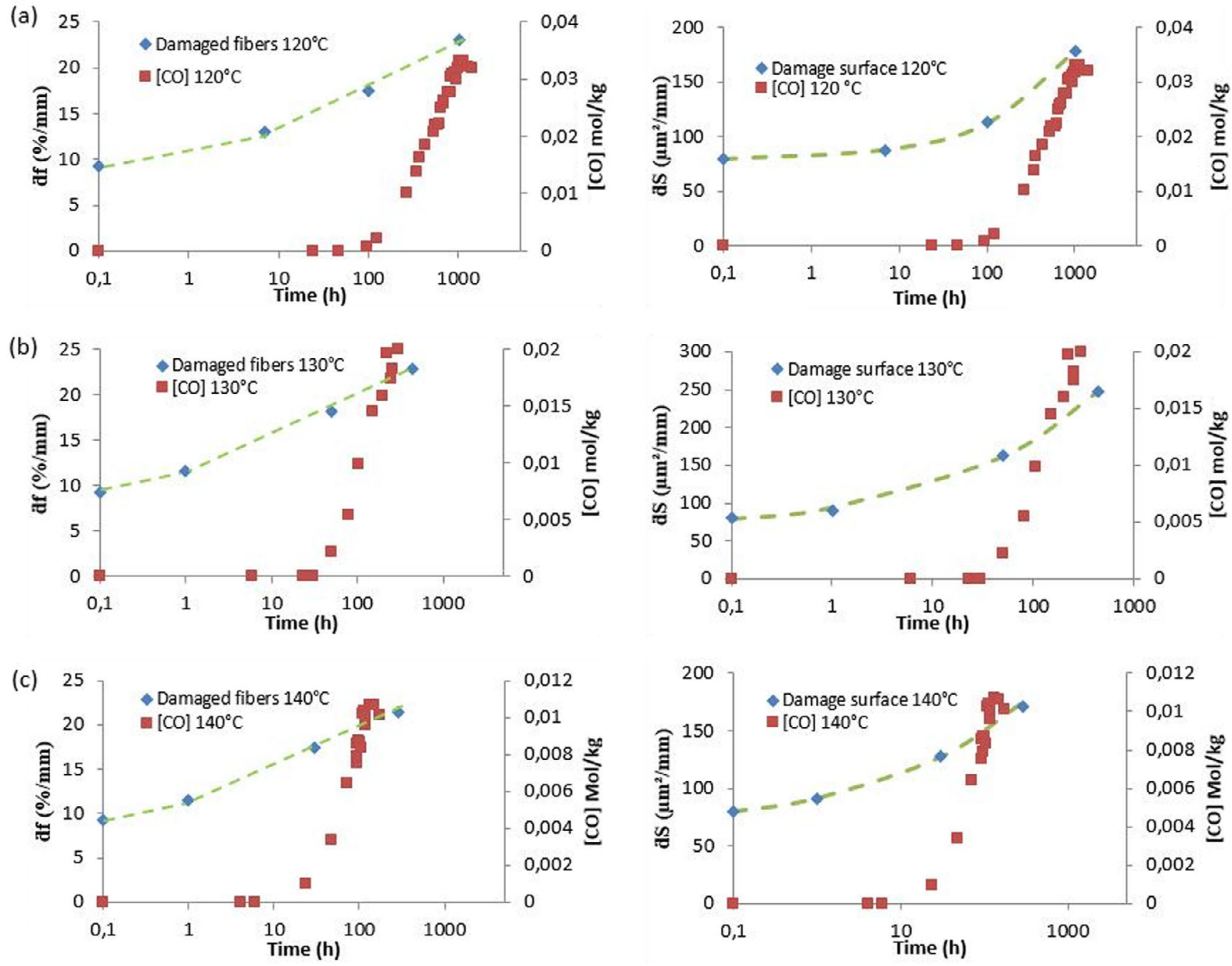

FIG. 8. Kinetic curves of damaged fibers and damage surface through aging (a) $120^{\circ} \mathrm{C}$, (b) $130^{\circ} \mathrm{C}$, and (c) $140^{\circ} \mathrm{C}$. [Color figure can be viewed at wileyonlinelibrary.com]

direct link between aging and damage allowing to establish a behavior law linking the chemical parameters of aging ([CO] dependent on time and temperature) and the mechanical ones.

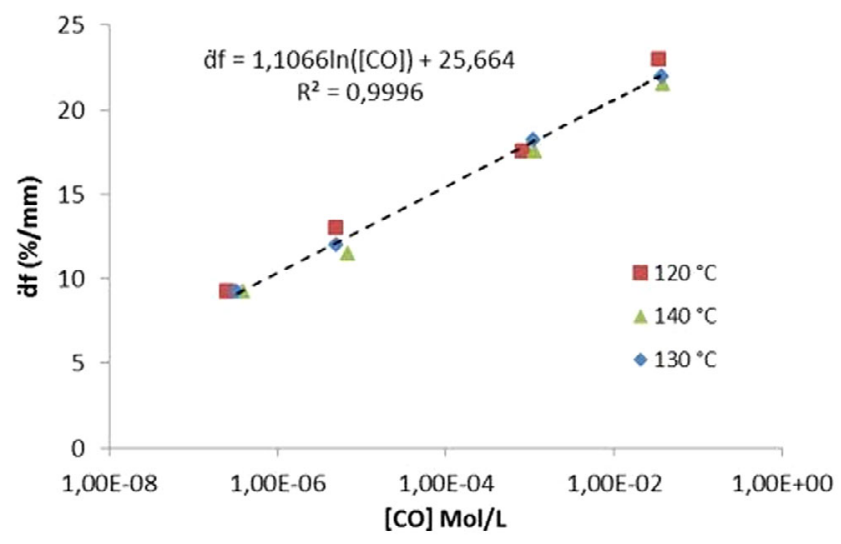

FIG. 9. Kinetic curves of damaged fibers as function of the carbonyl concentration in the material. [Color figure can be viewed at wileyonlinelibrary.com]
Hence, the micro-cracks density of local damage, $d f$, is determined directly as function of $[\mathrm{CO}]$ for a given strain that the specimen undergoes. It can be said then that local damage density is function of the carbonyl concentration, strain, exposure time and temperature:

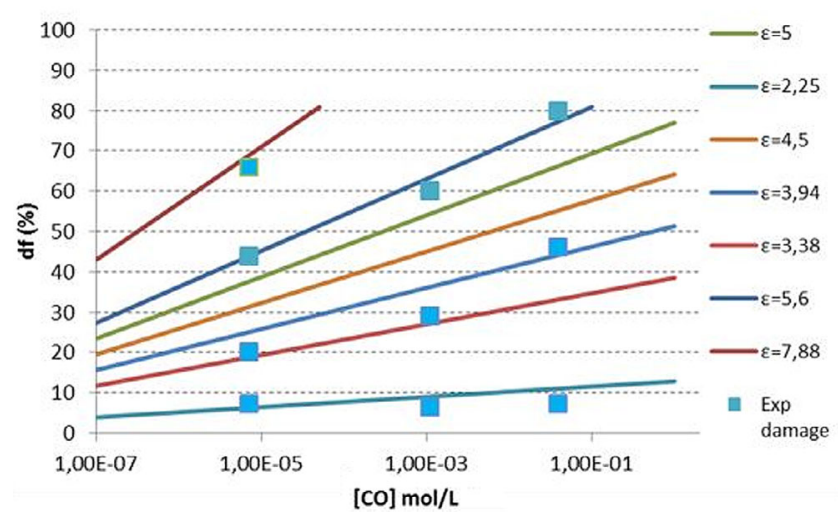

FIG. 10. Numerical fibers damage evolution at a given strain $(\varepsilon) V s$ experimental data. [Color figure can be viewed at wileyonlinelibrary.com] 


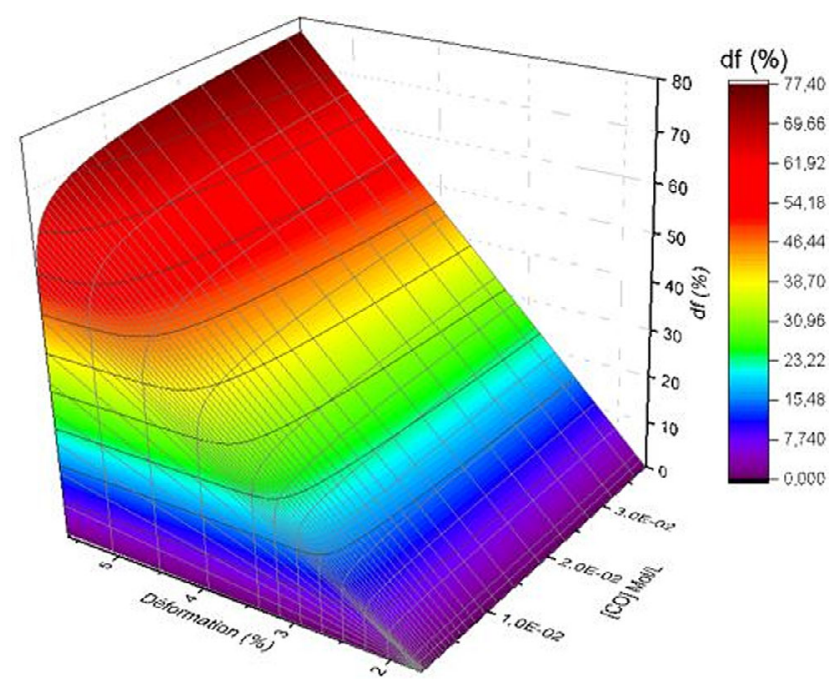

FIG. 11. Numerical damage density and oxidation product coupling. [Color figure can be viewed at wileyonlinelibrary.com]

$$
d f=f\left([C O]_{(t, T)}, \varepsilon\right) .
$$

Figure 10 represents the numerical curves of local damage density for different given strain and the experimental measured damage. It is clear that the adopted numerical approach predicts well the real occurred local damage.

As a result, the local damage generated within the composite as a result of a given deformation, that does not exceed $7 \%$, at any state of thermal aging (exposure time and temperature) can be determined up to a values not exceeding the $80 \%$ as described in Fig. 11.

\section{CONCLUSION}

The damage mechanisms and evolutions for a recycled short CFs-reinforced polymer subjected to thermal aging have been investigated using in situ three points bending tests. Experimental results showed that the thermal aging strongly affects the damage mechanisms threshold and kinetic. The predominant damage mechanisms are fiber/ matrix debonding and matrix cracking with the increase of exposure time. Furthermore, the fiber/matrix interface weakens during thermal oxidation and small micro-cracks around the fibers appear promoting thus the early damage initiation. Based on the tests observations, the damage chronology lies to a fiber/matrix debonding at the stress yield followed by micro-crack growth linking the closest debonds from other fibers through matrix cracking. During the induction time, the percentage of damaged fibers is higher than that of the virgin sample and shows a higher linear increase once the induction time occurs. As for the damage surface kinetics, they display a slight rise during the first hour of exposure followed by an exponential one just before the end of induction period. Furthermore, it has been proved that the micro-cracks density of local damage is function of the carbonyl concentration, strain, exposure time, and temperature.
This approach can be also developed under dynamic solicitation. Indeed, interrupted high strain rate tension tests as well as in situ tensile tests can help not only to determine the damage at deformations beyond $7 \%$ but also at different loading speeds.

The current experimental findings on thermal aging effects on the physical aspect of damage are important for identifying local damage data. Indeed, there are also micromechanical models in which the damage is taken into account at the microscopic scale. These are introduced using local damage criteria to predict the local state of cracking and the resulting macroscopic properties. An interesting perspective would therefore be to identify the parameters of these criteria using the behavior law identified in this study. Thus, the resulting micromechanical model would also be a function of the parameters of the kinetic predictive model of aging. As a result, a global multi-scale and multi-physical micromechanical model could be identified and introduced into industrial calculation codes.

\section{REFERENCES}

1. G. Bos EU waste legislation and the composites industry. Seminar on recycling of composite materials, IFP SICOMP, Molndal, Sweden (14th-15th May 2002).

2. S.J. Pickering, Compos. A, 37, 1206 (2006).

3. L. Yang, E.R. Sáez, U. Nagel, and J.L. Thomason, Compos. A Appl. Sci. Manuf., 72, 167 (2015).

4. S. Feih, A.P. Mouritz, and S.W. Case, Compos. A Appl. Sci. Manuf., 76, 255 (2015).

5. T. Suzuki, J. Takahashi Prediction of energy intensity of carbon fiber reinforced plastics for mass-produced passenger cars. The Ninth Japan International SAMPE Symposium (2005).

6. M.F. Arif, F. Meraghni, Y. Chemisky, N. Despringre, and G. Robert, Compos. B, 58, 487 (2014).

7. L. Távara and V. Mantič, Mech. Res. Commun., 84, 148 (2017).

8. S. Han, L.W. Yangb, T. Liu, X. Sun, R. Jiang, W.G. Mao, and Z.H. Chen, Mater. Des., 131, 265 (2017).

9. Z. Jendli, F. Meraghni, J. Fitoussi, and D. Baptiste, Compos. Sci. Technol., 69, 97 (2009).

10. F. Meraghni, F. Desrumaux, and M.L. Benzeggagh, Compos. Sci. Technol., 62, 2087 (2002).

11. J. Fitoussi, N. Bourgeois, G. Guo, and D. Baptiste, Comput. Mater. Sci., 5, 87 (1996).

12. N. Achour, G. Chatzigeorgiou, F. Meraghni, Y. Chemisky, and J. Fitoussi, Int. J. Mech. Sci., 103, 297 (2015).

13. N. Sato, T. Kurauchi, S. Sato, and O. Kamigaito, J. Mater. Sci., 26, 3891 (1991).

14. H. Bouaziz, O. Brinza, N. Haddar, M. Gasperini, and M. Feki, Mater. Character., 123, 106 (2017).

15. D.J. Mortell, D.A. Tanner, and C.T. McCarthy, Compos. Sci. Technol., 105, 118 (2014).

16. E. Richaud, F. Farcas, B. Fayolle, L. Audouin, and J. Verdu, Polym. Degrad. Stab., 92, 118 (2007).

17. B. Fayolle, L. Audouin, and J. Verdu, Polymer, 45, 4323 (2003). 
18. B. Fayolle, L. Audouin, and J. Verdu, Polym. Degrad. Stabil., 70, 333 (2000).

19. R. Bertrand, O. Caty, V. Mazars, S. Denneulin, P. Weisbecker, J. Pailhes, G. Camus, and F. Rebillat, J. Eur. Ceram. Soc., 37, 3471 (2017).

20. W. Shaoquan, D. Shangli, G. Yu, and S. Yungang, Mater. Des., 115, 213 (2017).

21. R.J. Tapper, M.L. Longana, H. Yu, I. Hamerton, and K. D. Potter, Compos. B Eng., 146, 222 (2018).
22. H. Meftah, S. Tamboura, J. Fitoussi, H. BenDaly, and A. Tcharkhtchi, J. Appl. Compos. Mater., 25, 1 (2017).

23. B. Mlekusch, Compos. Sci. Technol., 59, 547 (1999).

24. R. Bay and C.L. Tucker III, Polym. Compos., 13, 1317 (1992).

25. R. Bay and C.L. Tucker III, Polym. Compos., 13, 1332 (1992).

26. S. Tamboura, H. Meftah, J. Fitoussi, H. BenDaly, and A. Tcharkhtchi, J. Appl. Polym. Sci., 135, 46640 (2018).

27. S. Tamboura, H. Sidhom, and D. Baptiste, Matér. Tech., 3-4, 3 (2001). 